\title{
Acute Kidney Injury and Chronic Kidney Disease: A Bidirectional Road
}

\author{
Akut Böbrek Hasarı ve Kronik Böbrek Hastalığı: Iki Yönlü Yol \\ Meltem Gürsu, Sami Uzun*, Rümeyza Kazancıoğlu, Savaş Öztürk* \\ Bezmialem Vakıf University Faculty of Medicine, Department of Nephrology, Istanbul, Turkey \\ *Haseki Training and Research Hospital, Clinic of Nephrology, Istanbul, Turkey
}

Abstract

Acute kidney injury (AKI) and chronic kidney disease (CKD) have many common points regarding risk factors, etiology, clinical and laboratory factors. We aimed in this review to discuss the outcome, the risk of CKD, cardiovascular and overall mortality risk after AKI, and the mechanisms underlying the relationship between AKI and CKD.

Keywords: Acute kidney injury, chronic kidney disease, mortality, outcome
Akut böbrek hasarı $(A B H)$ ve kronik böbrek hastalı̆ının $(K B H)$ risk faktörleri, etiyoloji, klinik ve laboratuvar bulgular açısından pek çok ortak noktası bulunmaktadır. Bu derlemede $A B H$ sonrası sonlanımı, $\mathrm{KBH}$ riskini, kardiyovasküler ve tüm nedenlere bağlı mortaliteyi ve $\mathrm{ABH}$ ve $\mathrm{KBH}$ arasındaki ilişkinin altında yatan mekanizmaları tartışmayı amaçladık.

Anahtar Sözcükler: Akut böbrek hasarı, kronik böbrek hastalığı, mortalite, sonlanım

\section{Introduction}

Acute kidney injury (AKI) and chronic kidney disease (CKD) have many common features regarding risk factors, etiology, clinical and laboratory findings. However, the most important common similarity is their outcome. Moreover, both clinical entities are related with progressive loss of kidney function, decreased life quality, increased cardiovascular risk and mortality.

\section{Is Acute Kidney Injury a Risk Factor for Chronic Kidney Disease?}

The previous data was consistent with a good longterm outcome after AKI. Liano et al. (1) followed up 187 consecutive patients without known nephropathy and hospitalized after 1992 due to acute tubular necrosis (ATN) for a median of 7.2 years (7-22 years) after their discharge. Ten patients were lost-to-follow-up during this period and 95 patients died. The clinical evaluation of 58 of 82 patients who survived in years 2000-2001 revealed that $81 \%$ of them had normal renal functions. One-, 5-,
10- and 15-year survival rates were detected to be $89 \%$, $67 \%, 50 \%$ and $40 \%$, respectively. Survival was better in young patients, those who had ATN after trauma, patients without a comorbidity and those who were followed up in intensive care units. The authors commented that renal functions remained well in most of the patients although long-term mortality was high.

On the other hand, there is data in the literature showing that the long-term results are not so good after AKI. Ishani et al. (2) evaluated patients older than 67 years who were discharged after hospitalization in 2000 using Medicare and United States Renal Data System (USRDS) data. Patients with a history of AKI within the last two years and those who were diagnosed to have end-stage renal disease (ESRD) during hospitalization were excluded. Among the 233.803 patients involved, AKI was diagnosed in $3.1 \%$ of patients of whom $34.3 \%$ had history of CKD. The rate of ESRD was $0.5 \%$ in the overall group, and $25.2 \%$ of them were discharged with the diagnosis of AKI. The percentage of patients diagnosed with ESRD was 
similar to that of patients without a history of either AKI or CKD $(0.208 \%)$ and those with CKD $(1.988 \%)$, while this rate was $2.45 \%$ in patients with $\mathrm{AKI}$ and $7.94 \%$ in those with AKI on CKD (2). The risk of ESRD was $54 \%$ higher in patients with AKI compared to those with CKD. The presence of $A K I$ and CKD together increased the risk of ESRD markedly in comparison with patients with neither of them (hr: 41.19).

In their meta-analysis, Coca et al. (3) studied the observational and randomized controlled studies published about the subject between 1990 and 2007. The overall analysis of more than 3000 patients involved in the 13 studies revealed that the risk of ESRD increases after AKI (hr: 3.10) (3).

Therefore, studies state that AKI increases the risk of $C K D$, the progression of CKD, and ESRD (2-6).

\section{Is Acute Kidney Injury Related with Mortality?}

Ishani et al. (2) analyzed the mortality rates in their previously mentioned study. Patients with AKI had 2.38 times higher mortality rate compared to patients without AKI. When compared to patients with normal renal functions, mortality rate was 1.45 times higher in patients with CKD, 2.48 times in those with AKI and 3.24 times in patients with both AKI and CKD (2).

Chertow et al. (4) analyzed the mortality rate in 19.982 patients with one or two creatinine level measured during their hospitalization and in 9.205 patients with two or more measurements of creatinine. The mortality rate increased parallel to serum creatinine levels when patients were grouped as those with a serum creatinine level of 0.3-0.4 mg/dL [odds ratio (OR): 4.1 ], $0.5-0.9 \mathrm{mg} / \mathrm{dL}$ (OR: 6.5), $1.0-1.9 \mathrm{mg} / \mathrm{dL}$ (OR: 9.7 ) and $\geq 2 \mathrm{mg} / \mathrm{dL}$ (OR: 16.4) (4).

Coca et al. (5) studied the risk of 30-day mortality in patients with small acute changes in serum creatinine levels in their meta-analysis. The relative risk of mortality was $1.8,3.0$ and 6.9 times higher in patients showing $10-24 \%, 25-49 \%$ and $>50 \%$ increase in serum creatinine levels, respectively compared to the control group. It was concluded that even small changes in serum creatinine level was related with worse short- and long-term outcomes whether or not there was CKD.

Lo et al. (6) reported in their study that 322 patients had CKD during 10.344 patient-years of follow-up, and ESRD developed in 41 of them. The rate of CKD was 47.9/100 patient years and $1.7 / 100$ patient years in patients with or without a history of AKI, respectively. Moreover, all the 41 patients who had ESRD were in the AKI group. There were 703 patients who suffered dialysis-requiring. ARF of these patients, 295 died in hospital and ESRD developed in 65 of them. Mortality and ESRD was recorded in 6416 and 22 patients respectively among $562.076 \mathrm{AKI}$ cases without need for dialysis. Dialysis requiring AKI was shown to increase CKD risk by 28 times and death risk by 2.3 times when other intervening factors were excluded.

Patients with AKI requiring in-hospital dialysis were compared with those who did not require dialysis for at least 30 days following discharge in a Canadian study (7). It was reported that the previous group had three times higher risk of ESRD while mortality rate did not increase.

Amdur et al. (8) studied patients who were hospitalized due to either AKI or ATN between years 1999 and 2005, and compared them with a control group including patients with pneumonia or myocardial infarction (MI). Patients were divided into four groups: ATN $(+)$, pneumonia or MI (-) (345 patients); AKI (+), ATN (-), pneumonia or MI (-) (5021 patients); pneumonia or MI (+), AKI (-), ATN (-) (62.850 patients), stage 3-5 CKD (+) and ATN or pneumonia or $\mathrm{MI}(+)$ (44.076 patients). The mortality was increased 1.12 times in patients with AKI and 1.2 times in those with CKD compared to the control group.

The 2007 Annual Data of the USRDS reported that AKI increased the risk of rehospitalization, ESRD and death in patients with CKD (9).

Hence, we can conclude that the long-term outcome of $A K I$ is not good; and is related with the increased risk of CKD, ESRD and death.

\section{Which Patients Have Higher Risk for Chronic Kidney Disease and Mortality After an Attack of Acute Kidney Injury?}

Previous studies reported increased mortality in patients with AKI (10). Chawla et al. (11) studied 5.351 patients hospitalized due to AKI or ATN between 1999 and 2005 and compared them with 15.917 control subjects. The number of patients who developed stage-4 CKD was 728 in the patient group (13.6\%) and 1.348 in the control group (8.5\%). Advanced age (OR: 1.01, $p=0.019)$, longer period under the risk (OR: 1.12, $\mathrm{p}=0.0004)$, need for renal replacement therapy (OR: $2.4 ; p=0.0063$ ), higher risk, injury, failure, loss of kidney function, and End-stage kidney disease score (OR: 1.88, $p<0.0001)$ and lower serum albumin (OR: $0.33, p<0.0001)$ were reported to be the risk factors for CKD.

Thakar et al. (12) evaluated 4.082 diabetics who had received health care between 1999 and 2004 and followed them until the end of 2008. Primary and secondary end points were the development of stage-4 CKD and all-cause mortality, respectively. Eight hundred and five attacks of AKI were recorded in 530 patients during the follow up. The number of AKI attacks was 1 in $70 \%$ and 2 or more in $30 \%$ of patients. The risk factors for development of stage-4 CKD were found to be occurrence of AKI in 
hospital, higher basal serum creatinine level, presence of proteinuria, hypertension, and female gender. CKD risk was highest in patients who had three attacks of AKI with the risk decreasing progressively in patients with two, one or no attacks of AKI (12).

Another study by Ozturk et al. (13) determined advanced age, lower initial creatinine and albumin levels at the first session as major factors affecting mortality in patients with AKI requiring dialysis. The mean number of hemodialysis sessions was higher in patients who survived after AKI attacks (13).

Therefore, need for renal replacement therapy and/or repeated AKI attacks increases the risk of CKD. The roles of gender, age, the place where it developed (home, hospitalclinic, and intensive care unit), etiology, comorbidities and specific renal disease are controversial.

\section{Does Acute Kidney Injury Increase the Cardiovascular Risk?}

James et al. (14) retrospectively evaluated 14.782 patients who had coronary angiography between 2004 and 2006 for the rate of AKI and long-term outcome including mortality, ESRD, cardiovascular events and hospitalization. AKI was more frequent in patients who had high serum creatinine levels before angiography and those with proteinuria with the stage of AKI increasing as estimated glomerular filtration rate (eGFR) decreased. Moreover, AKI risk was higher in patients with diabetes mellitus, heart failure, cerebrovascular disease, peripheral artery disease, and chronic pulmonary or liver disease. The risk of death and ESRD was lower in patients without AKI; higher in patients with stage $1 \mathrm{AKI}$; and highest in those with stage 2-3 AKI. Hospital stay was also longer in patients with AKI. The authors stated that AKI increased the risk of not only mortality and ESRD, but also hospitalization due to $\mathrm{Ml}$ and heart failure.

Stroke patients were studied in another study in which patients with renal dysfunction were found to have higher risk for mortality and new cardiovascular events (15).

Patients who had AKI or MI between 1999 and 2005 according to the records of veterans affairs database were studied more recently (16). They were divided into three groups as AKI group, $\mathrm{Ml}$ group and $\mathrm{AKI}+\mathrm{Ml}$ group after exclusion of patients with eGFR<45 mL/min/1.73 $\mathrm{m}^{2}$. Primary end points were death and new renocardiac event in this study that included 36.980 patients. Death rate was highest in $\mathrm{AKI}+\mathrm{Ml}$ group (57.5\%) and lowest in $\mathrm{MI}$ group (32.3\%). Major renocardiac events were more frequent in $\mathrm{AKI}+\mathrm{Ml}$ group compared to $\mathrm{MI}$ group. Moreover, death, hospitalization due to stroke, heart failure, and recurrent $\mathrm{MI}$ were more common in patients who had AKI.
Consequently, it can be concluded that the risk of major cardiovascular event increases in patients with AKI independent from the presence of a previous cardiovascular disease.

\section{How Does Acute Kidney Injury Increase the Risk of Cardiovascular Mortality?}

Although AKI is a localized tissue damage, it triggers systemic inflammatory response, irrespective of the initial cause (17). The chemoattractants released from activated endothelial cells and damaged epithelial cells cause migration of neutrophils, monocyte/macrophages and lymphocytes. Cytokines, chemokines, reactive oxygen products and nitrogenous products released from these cells cause acute aseptic inflammation.

This fact leads to the question whether renoprotection is possible with inhibition of inflammatory infiltration or not. Several studies have been carried out with ATN models. Ischemic injury stimulates toll-like receptors (TLR) leading to exocytosis of Weibel-Palade bodies from endothelial cells. This leads to release of von Willebrand factor, interleukin (IL)-8, angiopoietin-2, eotaxin, endothelin-1, and other biologically active substances that cause stem cell mobilization, inflammation, coagulation and increased vascular permeability. It is thought that substances released from Weibel-Palade bodies have proinflammatory effects in the early period while they may have pro-regenerative roles in the later stages. Therefore, selective inhibition of pro-inflammatory mediators may be a realistic approach in the future.

Concomitant with this pathway, purine metabolism is accelerated due to ischemic damage leading to increased production of uric acid which is known to be the prototype alarm signal. Uric acid together with high mobility group box-1 protein provides engagement of endothelial progenitor cells to the ischemic tissue and release of proinflammatory cytokines.

Systemic inflammatory response may affect other organs, such as heart, lung and liver, increasing the mortality risk further. Thus, patients die 'with AKI' but not 'due to AKI'.

\section{The Mechanisms Underlying the Pathophysiology of Chronic Kidney Disease after Acute Kidney Injury}

There are many studies showing increased frequency of CKD after AKI $(2,3,6,18-20)$. However, it is stated in all of these articles that the pathophysiology is not clear.

Loss of tubular brush border, loss of tubular cells, proximal tubular dilation, cylinders within the distal tubules, and areas of cellular regeneration are among the findings seen following ATN (20). Although there are many 
genes reported to be related to these events, there is no specific one. Endothelial damage in ATN decreases renal blood flow. Increased endothelin level and decreased nitric oxide level aggravates ischemia. Meanwhile, an increase in the expression of both intracellular adhesion molecules (endothelium mediated damage), and TLRs (epithelial damage caused by ischemia related cytokines), and a decrease in peroxisome proliferator-activated receptors activation take place.

Moreover, neutrophils, natural killer cells and macrophages become activated by stimulation of the immune system. Complement system and various adhesion molecules are activated and release of tumor necrosis factor (TNF)-alpha, IL-6 and IL-8 are increased (21).

Basile et al. (22) analyzed renal biopsy samples from male rats obtained four, eight and 40 weeks after ischemia reperfusion injury or sham operation. The authors found that some of the tubules were not repaired and there was interstitial hypercellularity four weeks after acute renal failure. Tubular structure was normal at the $8^{\text {th }}$ week except hypercellularity while glomerular atrophy in some regions and glomerular hypertrophy in others, cellular

\begin{tabular}{|l|}
$\begin{array}{l}\text { Table. Summary of acute kidney injury related main risks } \\
\text { regarding chronic kidney disease, end-stage renal disease, } \\
\text { mortality and inflammation }\end{array}$ \\
\hline Increased risk of CKD: \\
\hline AKI increases the risk of CKD and the progression of CKD $(2-6)$ \\
\hline Repeated AKI attacks increases the risk of CKD markedly $(12,13)$ \\
\hline Increased risk of ESRD: \\
\hline AKI increases risk of ESRD (3) \\
\hline AKI and CKD together increase the risk of ESRD markedly (2) \\
\hline AKI on CKD increases the progression of CKD to ESRD (6) \\
\hline Increased mortalitiy: \\
\hline AKI increases patients' mortality rates (2,10) \\
\hline Mortality increases parallel with the severity of the AKI (4-5,14) \\
\hline Dialysis requiring AKI increases death risk (6) \\
\hline $\begin{array}{l}\text { Risk of major cardiovascular events increases in patients with AKI } \\
\text { independent from the presence of a previous cardiovascular disease } \\
\text { (16) }\end{array}$ \\
\hline $\begin{array}{l}\text { Young patients, those who had ATN after trauma, patients without } \\
\text { a comorbidity and those who were followed in intensive care units } \\
\text { have better survival rate (1) }\end{array}$ \\
\hline Increased systemic inflammation: \\
\hline AKI triggers systemic inflammatory response (17) \\
\hline This maybe irrespective of the initial reason \\
\hline $\begin{array}{l}\text { Systemic inflammatory response may affect other organs like heart, } \\
\text { kidneys, lung and liver increasing morbiditiy and mortality risk } \\
\text { further }\end{array}$ \\
\hline $\begin{array}{l}\text { Legends for illustration: Mechanisms responsible for the progression AKI to CKD } \\
\text { CKD: Chronic kidney disease AKI: Acute kidney injury related, ATN: Acute } \\
\text { tubular necrosis, ESRD: End-stage renal disease }\end{array}$ \\
\hline
\end{tabular}

infiltration and tubulointerstitial scarring were observed at 40th week.

Zager et al. (23) compared the weight of ischemic and the contralateral kidneys of rats one day, one week and three weeks after unilateral ischemia-reperfusion injury. The weight of the ischemic kidney increased on the first day of ischemia, but started to decrease progressively thereafter, while the weight of the contralateral kidney increased progressively. TNF-alpha mRNA and membrane cofactor protein-1 mRNA levels in the ischemic kidney were higher compared to the contralateral kidney in the first day, reaching maximum levels in the first week, and decreasing thereafter. Transforming growth factor (TGF)- $\beta 1$ mRNA levels were reported to increase with time progressively (23).

Renal cortical endothelin-1 mRNA level was studied in another study 24 hours and two weeks after unilateral ischemia reperfusion (19). Endothelin level was higher in the ischemic kidney at both time periods being more prominent at the 2nd week (19). The lack of increase in the plasma and contralateral kidney led to the idea that endothelin synthesis was local. Another interesting finding was that the increase was mainly in endothelin A receptor mRNA (19). The authors reported that atrosentan given before and after ischemia did not prevent the decrease in kidney weight (19).

Similarly, Zager et al. (23) revealed a prominent decrease three weeks after ischemia reperfusion injury and TGF-beta RNA level and increased ratio of TGF-beta acetylation.

Endothelin has prime role in ischemic renal damage. It decreases blood flow by vasoconstriction and causes inflammation and oxidative stress (18). Endothelin-A receptor antagonists may be effective by blocking these steps (18).

Systemic and intrarenal hypertension, glomerular hyperfiltration, tubular hypertrophy and atrophy,

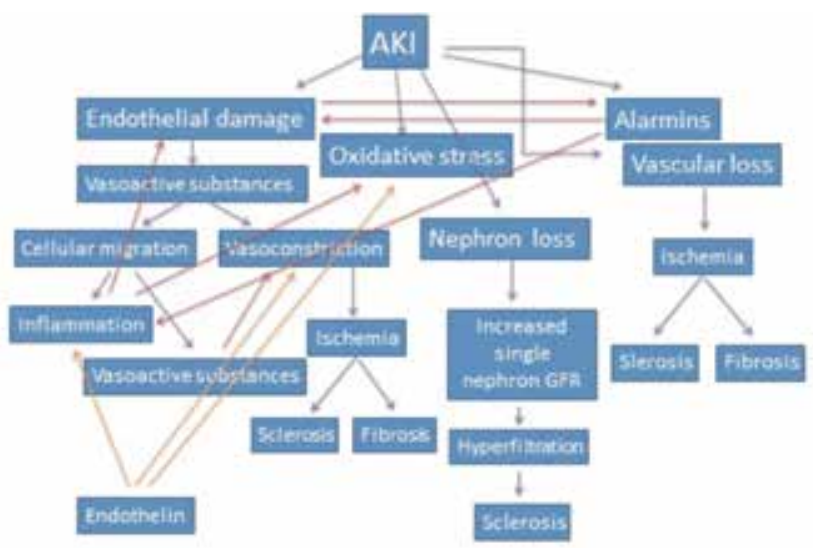

Figure. The Mechanisms Underlying the Pathophysiology of chorinic kidney disease after acute kidney injury AKI: Acute kidney injury related, GFR: Glomerular filtration rate 
tubulointerstitial fibrosis, progressive glomerular sclerosis, arteriosclerosis, genetic propensity, defects in humoral response, uncontrolled apoptosis, abnormal responses of epithelial cells, pericytes, myofibroblasts and bone marrow cells, defects in differentiation, proinflammatory signals, and progressive capillary loss are all active in the process leading AKI to CKD (24-26).

These mechanisms are summarized in the Figure.

\section{Is Chronic Kidney Disease a Risk Factor for Acute Kidney Injury?}

The principle risk factors described are advanced age, black race, genetic factors, hypertension, diabetes mellitus, and metabolic syndrome $(2,4,27)$. Above all of them, CKD increases the risk of AKI more than 10 times $(2,9,27)$.

Hsu et al. (28) compared patients who had AKI during hospitalization with those who did not have. The mean eGFR level before hospitalization was lower in the AKI group. Hypertension, diabetes mellitus and proteinuria were reported to be the other risk factors for AKI (28).

Patients with CKD are at risk of having temporary decreases in renal functions. Distorted autoregulation, abnormal vasodilation, increased sensitivity to diuretics and nephrotoxic agents, and age-related changes in renal physiology may be the underlying factors.

Another facilitative factor may be heart failure that is common in patients with CKD $(25,29)$. CKD has also been shown in animal models to increase sepsis-related AKI by intervening vascular endothelial growth factor and highmobility group box 1 protein (30). Roles of specific gene expressions and transplantation, epigenetic changes and uremic milieu are still subject of debate.

AKI related main risks about the topic were summarized in the Table.

\section{Conclusion}

In conclusion, AKI is not innocent even after recovery of renal functions. It is associated with increased risk of CKD. Need for renal replacement therapy and/or repeated AKI attacks increases the risk of CKD. AKI also increases cardiovascular mortality. Physicians should be alert dealing with AKI about cardiovascular events, and should follow these patients after full or partial recovery of renal functions.

\section{Ethichs}

Peer-review: Internally peer-reviewed.

\section{Authorship Contributions}

Surgical and Medical Practices: Meltem Gürsu. Concept: Meltem Gürsu, Rümeyza Kazancıoğlu. Design: Sami Uzun, Savaş Öztürk. Data Collection or Processing: Meltem Gürsu, Sami Uzun. Analysis or Interpretation:
Rümeyza Kazancıoğlu, Savaş Öztürk. Literature Search: Meltem Gürsu, Sami Uzun. Writing: Meltem Gürsu.

Conflict of Interest: No conflict of interest was declared by the authors.

Financial Disclosure: The authors declared that this study received no financial support.

\section{References}

1. Liano F, Felipe C, Tenoiro MT, et al. Long-term outcome of acute tubular necrosis: a contribution to its natural history. Kidney Int 2007;71:679-86.

2. Ishani A, Xue JL, Himmelfarb J, et al. Acute kidney injury increases risk of ESRD among elderly. J Am Soc Nephrol 2009;20:223-8.

3. Coca SG, Singanamala S, Parikh CR. Chronic kidney disease after acute kidney injury: a systematic review and metaanalysis. Kidney Int 2012;81:442-8.

4. Chertow MG, Burdick E, Honour M, Bonventre JV, Bates DW. Acute kidney injury, mortality, length of stay, and costs in hospitalized patients. J Am Soc Nephrol 2005;16:3365-70.

5. Coca SG, Peixoto AJ, Garg AX, Krumholz HM, Parikh CR. The prognostic importance of a small acute decrement in kidney function in hospitalized patients: a systematic review and meta-analysis. Am J Kidney Dis 2007;50:712-20.

6. Lo LJ, Go AS, Chertow GM, et al. Dialysis-requiring acute renal failure increases the risk of progressive chronic kidney disease. Kidney Int 2009;76:893-9.

7. Wald R, Quinn RR, Luo J, et al. Chronic dialysis and death among survivors of acute kidney injury requiring dialysis. JAMA 2009;302:1179-85.

8. Amdur RL, Chawla LS, Amodeo S, Kimmel PL, Palant CE. Outcomes following diagnosis of acute renal failure in U.S. veterans: focus on acute tubular necrosis. Kidney Int 2009;76:1089-97.

9. USRDS 2007 Annual Data Report. http://www.usrds.org/ atlas07.aspx.

10. Star RA. Treatment of acute renal failure. Kidney Int 1998;54:1817-31.

11. Chawla LS, Amdur RL, Amodeo S, Kimmel PL, Palant CE. The severity of acute kidney injury predicts progression to chronic kidney disease. Kidney Int 2011;79:1361-9.

12. Thakar CV, Christianson A, Himmelfarb J, Leonard AC. Acute kidney injury episodes and chronic kidney disease risk in diabetes mellitus. Clin J Am Soc Nephrol 2011;6:2567-72.

13. Ozturk $S$, Arpaci $D$, Yazici $H$, et al. Outcomes of acute renal failure patients requiring intermittant hemodialysis. Ren Fail 2007;29:991-6.

14. James MT, GhaliWA, Knudtson ML, et al. Associations between acute kidney injury and cardiovascular and renal outcomes after coronary angiography. Circulation 2011;123:409-16.

15. Tsagalis G, Akrivos $T$, Alevizaki $M$, et al. Renal dysfunction in acute stroke: an independent predictor of long-term all combined vascular events and overall mortality. Nephrol Dial Transplant 2009;24:194-200. 
16. Chawla LS, Amdur RL, Shaw AD, Faselis C, Palant CE, Kimmel $\mathrm{PL}$. Association between $\mathrm{AKI}$ and long-term renal and cardiovascular outcomes in United States veterans. Clin J Am Soc Nephrol 2014;9:448-56.

17. Ratliff BB, Rabadi MM, Vasko R, Yasuda K, Goligorsky MS. Messengers without borders: mediators of systemic inflammatory response in AKI. J Am Soc Nephrol 2013;24:52936.

18. Dhaun N, Webb DJ. The road from AKI to CKD: the role of endothelin. Kidney Int 2013;84:637-8.

19. Zager RA, Johnson AC, Andress D, Becker K. Progressive endothelin-1 gene activation initiates chronic/end stage renal disease following experimental ischemic-reperfusion injury. Kidney Int 2013;84:703-12.

20. Reichel RR. Acute kidney injury: quoi de neuf? Ochsner J 2014;14:359-68.

21. Leemans JC, Stokman G, Claessen $N$, et al. Renal-associated TLR2 mediates ischemia/reperfusion injury in the kidney. J Clin Invest 2005; 115:2894-903.

22. Basile DP, Donohoe D, Roethe K, Osborn JL. Renal ischemic injury results in permanent damage to peritubular capillaries and influences long-term function. Am J Physiol Renal Physiol 2001;281:887-99.

23. Zager RA, Johnson AC, Becker K. Acute unilateral ischemic renal injury induces progressive renal inflammation, lipid accumulation, histone modification, and "end-stage" kidney disease. Am J Physiol Renal Physiol 2011;301:1334-45.

24. Chawla LS, Kimmel PL. Acute kidney injury and chronic kidney disease: an integrated clinical syndrome. Kidney Int 2012;82:516-24.

25. Venkatachalam MA, Griffin KA, Lan R, Geng H, Saikumar $P_{\text {, }}$ Bidani AK. Acute kidney injury: a springboard for progression in chronic kidney disease. Am J Physiol Renal Physiol 2010;298:1078-94.

26. Hostetter TH. Progression of renal disease and renal hypertrophy. Annu Rev Physiol 1995;57:263-78.

27. Xue JL, Daniels F, Star RA, et al. Incidence and mortality of acute renal failure in Medicare beneficiaries, 1992 to 2001. J Am Soc Nephrol 2006;17:1135-42.

28. Hsu CY, Ordonez JD, Chertow GM, Fan D, McCulloch CE, Go AS. The risk of acute renal failure in patients with chronic kidney disease. Kidney Int 2008;74:101-7.

29. Berk BC, Fujiwara K, Lehoux S. ECM remodeling in hypertensive heart disease. J Clin Invest 2007;117:568-75.

30. Leelahavanichkul A, Huang $Y, H u ~ X$, et al. Chronic kidney disease worsens sepsis and sepsis-induced acute kidney injury by releasing High Mobility Group Box Protein-1. Kidney Int 2011;80:1198-211. 